\title{
Fragmento de osso humano atuando como projétil secundário decorrente de explosão
}

\section{Human bone fragment acting as a secondary projectile set off by an explosion}

João Baptista de Rezende-Neto1, TCBC-MG; Júnia Lira Carneiro²; Felipe Dias Sampaio³; João Batista Rodrigues Júnior ${ }^{4}$, ACBC-MG; Domingos André F. DRUMOND ${ }^{5}$,TCBC-MG

\section{INTRODUÇÃO}

$E^{x}$ xplosões têm a capacidade de causar dano a várias pessoas ao mesmo tempo. Usualmente, há quatro categorias de mecanismos envolvidos nas lesões por explosão ${ }^{1,2}$. A primeira delas resulta da "onda de energia", afetando principalmente vísceras ocas. A segunda categoria ocorre devido a debris e fragmentos da bomba arremessados em decorrência da explosão, os quais podem causar lesão contusa ou penetrante. O próprio corpo humano pode ser arremessado contra objetos sólidos ou ao solo, configurando a terceira categoria. Lesões por esmagamento, queimaduras, exacerbação de condições pré-existentes e lesões devidas a mecanismos distintos dos anteriormente descritos compõem a quarta categoria.

Poucos relatos de projéteis secundários originados de ossos humanos fraturados foram encontrados na literatura ${ }^{1}$. Descrevemos um caso apresentando este tipo de mecanismo de lesão decorrente da explosão acidental de uma bomba caseira.

\section{RELATO DO CASO}

Paciente do sexo masculino, 18 anos, foi admitido no Pronto Socorro alguns minutos após uma explosão. Ele estava próximo a uma pessoa que segurava um artefato explosivo (bomba caseira) que foi detonado inesperadamente. O escore da Escala de Coma de Glasgow do paciente era 15 e os sinais vitais incluíam pressão arterial igual a $130 \times 80 \mathrm{mmHg}$ e freqüência cardíaca igual a $88 \mathrm{bpm}$. O exame físico revelou ferida penetrante de $3 \times 4 \mathrm{~cm}$ na superfície anterior da coxa esquerda do paciente. A radiografia lateral do membro demonstrou uma área de densidade aumentada nas proximidades do fêmur esquerdo, sugerindo um fragmento de osso fraturado (Figura 1). Este foi retirado cirurgicamente sob anestesia local. Exame antropológico subsequente revelou que o fragmento de osso encontrado na ferida pertencia à falange proximal do quinto quirodáctilo esquerdo do paciente que segurava o artefato explosivo (Figura 2). Ambos os pacientes sobreviveram às suas lesões.

\section{DISCUSSÃO}

Embora lesões cranianas sejam a causa mais frequente de morte entre as vítimas de explosão, padrões pouco comuns de lesão podem ser encontrados. Entre eles estão: explosão pulmonar, ruptura do globo ocular, lesão cerebral traumática sem sinais físicos de trauma craniano, fratura de face pela implosão dos seios maxilares e perfurações de vísceras ocas sem penetração abdominal ${ }^{2}$. Mísseis secundários podem produzir cegueira ou trauma penetrante especificamente do olho e lesões cervicais amea-

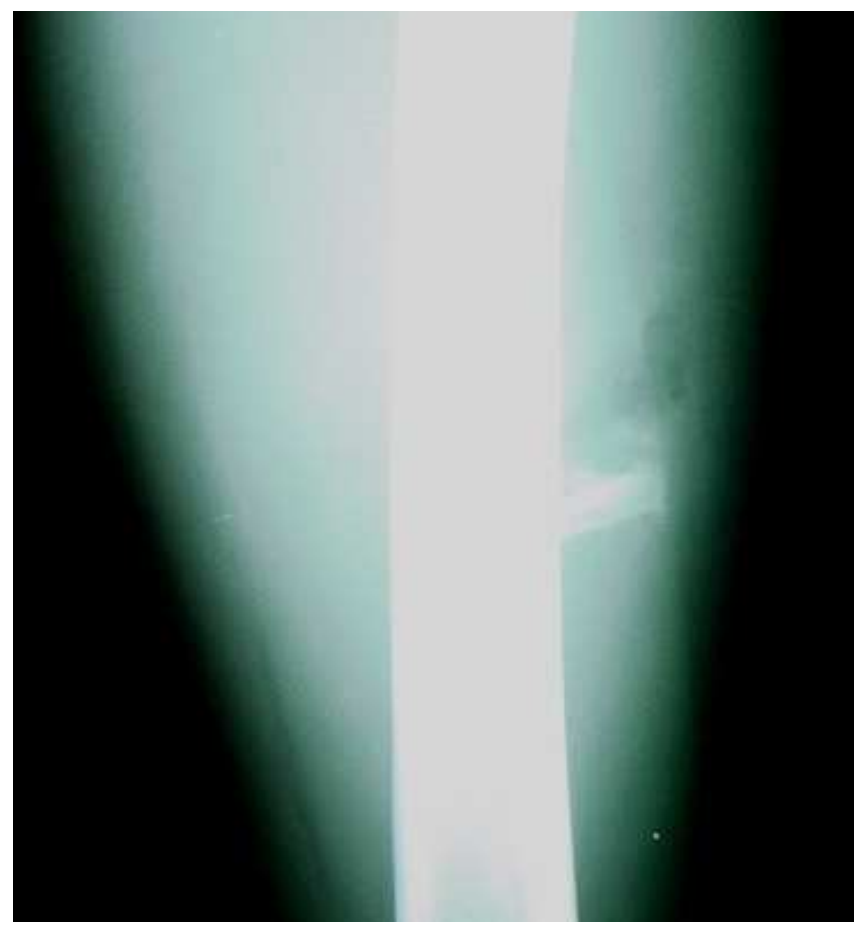

Figura 1 - Radiografia ântero-posterior mostrando fragmentos ósseos próximos ao fêmur esquerdo do paciente.

\footnotetext{
1. Professor Adjunto da Faculdade de Medicina da Universidade Federal de Minas Gerais, Belo Horizonte, MG; 2. Cirurgiã do Departamento de Cirurgia do Trauma Hospital João XXIII, Belo Horizonte, MG; 3. Cirurgião do Departamento de Cirurgia do Trauma Hospital João XXIII, Belo Horizonte, MG; 4. Cirurgião Hospital Odilon Behrens, Belo Horizonte, MG; 5. Chefe do Departamento de Cirurgia do Trauma Hospital João XXIII, Belo Horizonte, MG.
} 


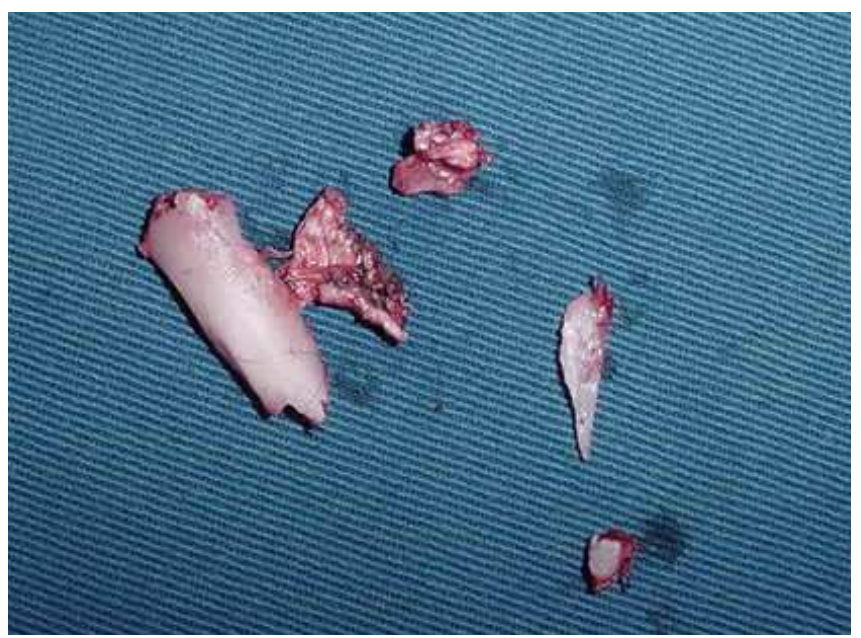

Figura 2 - Fragmentos ósseos removidos da coxa esquerda do paciente.

çadoras à vida até mesmo em longo prazo². Qualquer objeto arremessado por uma explosão pode se tornar um míssil secundário. Entretanto, é notavelmente raro encontrar fragmentos de osso humano ou outros tecidos inseridos no corpo de outro ser humano como resultado de explosão'. A abordagem desse tipo particular de lesão merece atenção especial. Em primeiro lugar, pode ser difícil identificar tecido ósseo alogênico em vítimas que apresentam fraturas cominutivas, especialmente em cenários com múltiplas vítimas. Em segundo lugar, há a possibilidade de transmissão de patógenos presentes no sangue e fluidos corporais ${ }^{1,3}$. Os vírus das hepatites B e C (HBV e HCV), o vírus da imunodeficiência humana (HIV) e o vírus linfotrópico humano de células T tipo 1 (HTLV-1) são os patógenos mais importantes desse tipo de transmissão ${ }^{4}$. Útil também é a informação sobre a prevalência do HBV, HCV, HIV e HTLV-1 na população ${ }^{4}$.

Em acidentes percutâneos, o risco de transmissão do HIV é de $0,3 \%$, do HCV de 1,8\% e do HBV de 1 a
$31 \%$, dependendo dos antígenos (HBsAg, HBeAg) presentes no soro do paciente-fonte ${ }^{5}$. Embora a informação a respeito da exposição a patógenos seja praticamente impossível em cenários de explosão com múltiplas vítimas (como em ações terroristas), essa informação é de grande valor para implementar profilaxia pós-exposição'

Segundo o Ministério da Saúde (MS), a quimioprofilaxia nos casos de exposição ocupacional percutânea ao HIV baseia-se no uso do AZT durante 28 dias, sendo iniciada no máximo até 72 horas após exposição, obtendo efeito protetor de $81 \%$. No caso do HBV, a profilaxia depende da situação vacinal do acidentado e da sorologia do paciente fonte. Não existe nenhuma medida eficaz para redução do risco de transmissão do HCV após acidentes percutâneos 5 . O MS e o Centers for Disease Control and Prevention (CDC) não fornecem informações sobre profilaxia de transmissão do HTLV nesses $\operatorname{casos}^{4,5}$. Segundo o CDC, os protocolos sobre exposição ocupacional dos profissionais de saúde a fluidos corporais podem ser aplicados a outras pessoas em cenários semelhantes ${ }^{4}$.

No presente relato, não foi realizada pesquisa sobre infecção viral nem profilaxia para os vírus citados anteriormente. Devido à raridade do tipo de lesão apresentado e aos poucos trabalhos publicados sobre este assunto, não há condutas padronizadas ou protocolos sobre como atuar nesses casos. Dessa forma, demonstra-se a importância de se discutir sobre a pesquisa e profilaxia antiviral neste tipo de situação.

Infelizmente, com as mudanças que vêm ocorrendo nas ações criminosas em nosso meio e em ações terroristas no mundo, cirurgiões com pouca ou nenhuma experiência em ações militares serão confrontados com lesões por explosão mais freqüentemente ${ }^{1}$. Portanto, em pacientes vítimas de explosão é fundamental suspeitar de lesões incomuns para evitar que passem despercebidas e avaliar a possibilidade de contaminação cruzada.

\section{A B $\quad S \quad T$ R A C T}

We report a case of a secondary projectile emanated from a fractured human bone from a victim of a bomb explosion. We also refer to the potential of transmition of blood-borne or body fluid pathogens by this mechanism of injury.

Key words: Explosion. Wounds and injuries. Blast injuries. Bone and bones. Humans.

\section{REFERENCIAS}

1. Huller T, Bazini Y. Blast injuries of the chest and abdomen. Arch Surg. 1970;100(1):24- 30.

2. Wightman JM, Gladish SL. Explosions and blast injuries. Ann Emerg Med. 2001;37(6):664-78

3. Xeroulis G, Inaba K, Stewart TC, Lannigan R, Gray D, Malthaner $R$, et al. Human immunodeficiency virus, hepatitis $B$, and hepatitis C seroprevalence in a Canadian trauma population. J Trauma. 2005;59)1): 1 05-8.
4. U.S. Public Health Service. Updated U.S. Public Health Service guidelines for the management of occupational exposures to HBV $\mathrm{HCV}$, and HIV and recommendations for postexposure prophylaxis. MMWR Recomm Rep. 2001:50(RR-11):1-52.

5. Ministério da Saúde - Programa Nacional de DST/Aids. Recomendações para atendimento e acompanhamento de exposição ocupacional a material biológico: HIV e hepatites B e C. PN DST/ Aids. Brasília, 2004, 56p. 
Recebido em 08/04/2007

Aceito para publicação em 10/05/2007

Conflito de interesse: nenhum

Fonte de financiamento: nenhum

\section{Como citar este artigo:}

Rezende-Neto JB, Carneiro JL, Sampaio FD, Rodrigues Júnior JB,

Drumond DAF. Fragmento de osso humano atuando como projétil secundário decorrente de explosão. Rev Col Bras Cir. [periódico na Internet] 2012; 39(5). Disponível em URL: http://www.scielo.br/rcbc

Endereço para correspondência:

Domingos André Fernandes Drumond

E-mail: dandrefernandes@uol.com.br 